\title{
A MESOLITHIC SETTLEMENT IN SURREY
}

$\mathrm{T}$

HE discovery of a mesolithic village at Farnham, Surrey, was due in the first instance to Mr. W. F. Rankine, who established the fact of mesolithic occupation on the Farnham Valley Sewage Farm in 1929 in the course of a surface survey of the district. Trial excavations were carried out during 1930-35. Mr. J. G. D. Clark, recognizing the import. ance of the site, then undertook its systematic investigation. Excavations wero carried out by him in 1937-38, Mr. Rankine co-operating. A report on the results of the excavations has been prepared under their joint authorship and is now available ${ }^{1}$.

The village is situated to the north-east of Farnham on the gravel of the old course of the Blackwater at a height of $250 \mathrm{ft}$. abovo O.D. Water supply and geographical conditions combined to make the site attractive to early man, as is indicated by the discovery of archrological remains of many periods, ranging from Neolithic to Romano-British.

The trial excavations revealed the existence of some eighteen depressions in the gravel, some rich in worked and burnt flints, and most of them between three and four feet deep. The area sclected for intensive work was a small rectangle showing less evidence of surface disturbance than other parts of the site. Here in 1937 three pits were discovered. Theso had a reddish-brown soil infilling, rich in worked and burnt flints. From Pit I, nowhere more than three feet in depth below the modern surface, some 851 crackled and more than 3,464 worked fints were recovered, while in a fourth pit, located and cleared in 1938, in which the floor had been cut through the gravel into red clay, 10,709 worked flints and 3,880 burnt flints were found. This pit was shown to be situated in a sandy hollow in the naturo of a swallow hole, into which hints had been swept in mesolithic times. Flints were recovered to the number of 12,135 worked and $6,8+7$ calcined. No significant differences in type were shown by flints from different lovels. Evidences of Neolithic B occupation were found, but it is clear that the swallow hole had been choked with sand before neo. lithic peoples settled on the mesolithic site.

The size and contents of the pits and their general characteristics do not allow any doubt that they were dug as the floors of dwellings by the people whose worked flints were found in them. They were evidently intended for occupation over a considerable period of time; and in this connexion the existence of a permanent water-supply near by must be remembered. The excavation of these floors by their makers provided a certain amount of soil to serve for walls, on which roofs could be placed; but the irregular plan of the pits and the absence of post-holes argue against any kind of rigid framo construction. In regard to character and purpose, or mode of occupation, comparison may be instituted with the dwellings of Upper Palrolithic age investigated in Russia and Siberia and the earth. houses of recent circumpolar peoples.

Typological analysis of the flint implements found indicates a homogeneous industry, consisting of various types of microliths, of which slightly more than
30 per cent are geometric, flakes, scrapers, awls, burins, and core tools. Two techniques are to be noted, one core and the other flake. In the latter, microliths account for two-thirds of the whole.

Farnham is one of a number of sites in the area, extending to Aldershot, Guildford, Haslemere, and Bentley, on which the culture is essentially the same. Study of its distribution indicates the importance of geologico-ecological factors, and emphasizes the importance of water, and a subsoil of gravel or sand. Extending the survey to the south and east in Surrey, Sussex and parts of Kent, it would appear that the mesolithic sites are predominantly situated on the U-shaped band of Lower Greensand which surrounds the Weald, taking in sites at Dorking, Reigate, Red. hill, and so far as East Malling, near Maidstone. A mace from Blackdown, now in the Haslemere Museum (and similar finds elsewhere), resembles a form from the heart of the Maglemose culture, which goes back to Boreal times. It is, therefore, evident that Farnham, Silmeston, Horsham, and other closely related sites form a group of industries differing in detail, but having in common features not found in combination elsewhere. They occupy a well-defined geographical area on analogous geological formations; and they therefore belong to a narrowly distributed but self-standing culture, for which the term Horsham culture has been proposed.

The key to the wider affinities of the Horsham culture is afforded in its combination of microlithic and core-axe elements-a combination which can be matched only in the Maglemose culture. While, however, the Maglemose strain must be recognized, certain differences must be admitted. The proportion of core axes is lower in relation to the micro. liths; and the microlithic forms are more varied. The microliths resemble most closely the Middle Tardenoisian of north-east France and Belgium. The Horsham culture, then, must be regarded as being basically Maglemosian, with a strong influence from Middle Tardenoisian. It is known that Maglemose spread over land now submerged, leaving outliers above modern sea-level in Holderness, East Anglia, the valley of the Thames and its tributaries, and probably the Isle of Wight and its hinterland. It was no doubt on the fringe of this territory on the western verge of the Maglemose culture-spread that the Middle Tardenoisian entered Britain; and it can scarcely be a coincidence that the Horsham culture, showing elements from both, is situated precisely in the zono of contact between the two.

Throughout history Britain has benefited from a variety of movements and influences from a variety of Continental sources. Already in mesolithic times two separate influences are to be seen flowing into England, one predominantly northern and the other predominantly western in character. The Horsham culture typifies the development of the British people which, drawing its inspiration from many sources, has yet managed to acquire its own distinctive features.

1 Proc. Prehist. Soc., 5, 1; 1939. 